Artigo original

Hegemonia - Revista Eletrônica de Relações Internacionais do Centro Universitário Unieuro

ISSN: $1809-1261$

UNIEURO, Brasília, número 15, 2015, pp. 17-41.

Recebido em: $23 / 3 / 2015$

Avaliado em:18/4/2015

Aprovado em: 8/5/2015

\title{
O Esvaziamento Político dos Direitos Humanos a partir da Construção do Conceito de Humanidade
}

Andrey Borges Pimentel Ribeiro ${ }^{1}$ e Carlos Ugo Santander Joo ${ }^{2}$

Resumo: A construção do conceito de humanidade possibilitou o desenvolvimento dos direitos humanos e a concepção do ser enquanto sujeito desses direitos a partir de sua condição de humano. Mas, o desenvolvimento da compreensão humana se deu a partir de uma autonomia irrestrita do indivíduo, o qual transforma sua vontade em direitos gerando um movimento contínuo de expansão na esfera jurídica, em que tudo passa a ser objeto da mesma. Ao aumentar o objeto do direito e inventar direitos, o ser humano se torna sujeito desses mesmos direitos, em uma dupla acepção: (1) sujeito ativo e titular dos direitos; (2) sujeito passivo e sujeitado aos direitos. Esta dupla acepção dos direitos reflete nos direitos humanos, sendo que não há um limite para o que pode ser contemplado pelo direito, nem a título de sujeito, nem a título de objeto. O problema do trabalho consiste na ineficácia dos direitos humanos a partir do conceito de humanidade, sendo que a hipótese é que a construção moderna de tal conceito expandiu o objeto do direito esvaziando o escopo político de resistência dos direitos humanos. O objetivo deste artigo é analisar o efeito político do conceito de humanidade nos direitos humanos. Para tanto, é apresentado o conceito de humanidade e sua construção moderna. Em seguida, é tecida uma crítica filosófica apoiada em Costas Douzinas a tal conceito. Assim, é possível situar a acepção dupla dos direitos e dos direitos humanos e seus efeitos jurídicos e políticos, sendo que o principal efeito político é o esvaziamento da meta dos direitos humanos de compor a resistência.

Mestre em Ciência Política pela Universidade Federal de Goiás.

Professor da Universidade Federal de Goiás. 
Artigo original

Hegemonia - Revista Eletrônica de Relações Internacionais do Centro Universitário Unieuro

ISSN: $1809-1261$

UNIEURO, Brasília, número 15, 2015, pp. 17-41.

Palavras-chave: Direito; Político; Humanidade; Efeito; Resistência.

\section{Abstract}

The construction of the concept of humanity enabled the development of human rights and the concept of being as subject of those rights from their humanness. But the development of human understanding was given from an unrestricted autonomy of the individual, which will transform your rights in generating a continuous movement of expansion in the legal sphere, where everything becomes the same object. By increasing the object of law and invent rights, the human becomes the subject of those rights, in a double sense: (1) active subject and the rights holder; (2) taxable and subjected to rights. This double meaning of the rights reflected in human rights, and there is no limit to what can be covered by the law nor as a subject or as an object. The problem of the research is the inefficiency of human rights from the concept of humanity, and the hypothesis is that the modern construction of this concept expanded the object of the right deflating the political scope of resistance of human rights. The goal is to analyze the political effect of the concept of humanity in human rights. Thus, the concept of humanity and its modern construction is presented. It is then made a philosophical critique supported by Costas Douzinas such concept. Finally, it is possible to locate the double meaning of rights and human rights and its legal and political effects, and the main political effect is emptying the goal of human rights composing the resistance.

Keywords: Right; Politic; Humanity; Effect; Resistance.

\section{Introdução}

O direito contemporâneo é resultado da tradição filosófica moderna e seus aportes teoréticos, e os direitos humanos reforçam essa relação umbilical com a modernidade. Aliás, os direitos humanos se confundem com o próprio direito contemporâneo, tendo em vista que há uma expectativa de resolver os problemas do mundo, como o estabelecimento da paz, a preservação da natureza, as garantias 
Artigo original

Hegemonia - Revista Eletrônica de Relações Internacionais do Centro Universitário Unieuro

ISSN: $1809-1261$

UNIEURO, Brasília, número 15, 2015, pp. 17-41.

fundamentais, enfim, não tem existido um limite para o escopo normativo do (s) objeto ( $\mathrm{s}$ ) dos direitos humanos, e nesse viés, todo o direito passa a ser direito humano.

O problema do trabalho consiste na ineficácia dos direitos humanos a partir do conceito de humanidade, sendo que a hipótese é que a construção moderna de tal conceito expandiu o objeto do direito esvaziando o escopo político de resistência dos direitos humanos.

O objetivo deste artigo é analisar o efeito político do conceito de humanidade nos direitos humanos. Para tanto, é apresentado o conceito de humanidade e sua construção na modernidade. Em seguida, é tecida uma crítica filosófica apoiada em Costas Douzinas a tal conceito. Assim, é possível situar a acepção dupla dos direitos e dos direitos humanos e seus efeitos jurídicos e políticos, sendo que o principal efeito político é o esvaziamento da meta dos direitos humanos de compor a resistência.

Por fim, são apresentadas as considerações finais e referências bibliográficas utilizadas no presente artigo.

\section{A construção do conceito moderno de humanidade}

A noção do que seja a pessoa ${ }^{3}$ não é uma percepção natural. Pelo contrário, ao longo da história o entendimento sobre o que seja a pessoa tem sido modificado, portanto, é algo construído, tratandose de um conceito abstrato dinâmico que tem diversas facetas de acordo com o tempo e a localidade. Quando Aristóteles ${ }^{4}$ (2012, p. 18)

Utilizamos a nomenclatura "pessoa" como a mais genérica possível, pois no escopo do trabalho "humano", "indivíduo" e "homem" têm indicadores conceituais específicos histórica e filosoficamente.

Obviamente que a filosofia antiga é assaz variada e abriga séculos de discussões teóricas. Nesse sentido, a opção por Aristóteles reduz e muito o pensamento clássico, mesmo o grego; todavia, em razão da abrangência e influência aristotélica, o artigo o assume como um filósofo representativo para se reconstruir uma noção de como era percebida a pessoa. 
Artigo original

Hegemonia - Revista Eletrônica de Relações Internacionais do Centro Universitário Unieuro

ISSN: $1809-1261$

UNIEURO, Brasília, número 15, 2015, pp. 17-41.

refere-se à pessoa, ele a evidencia como um ser social, mas que se torna específico a partir da possibilidade de entendimento pela linguagem. Esta convivência social mediada pela fala caracteriza a pessoa em sua essência que a torna política por excelência, disto decorre o zoon politikon ${ }^{5}$ aristotélico.

Mas, nem todas as pessoas eram iguais na perspectiva grega, sobretudo nos escritos de Aristóteles. Aliás, o filósofo de Estagira ressaltava a condição da pessoa em termos mais pormenorizados, ao detalhar a "economia doméstica" de composição da família pelas relações "senhor e o escravo, o marido e a mulher, os pais e os filhos" (ARISTÓTELES, 2012, p. 19). Dependendo do tipo de relação, faixa etária e sexo, a pessoa tem um tipo de atribuição desde a família como a "pessoa ser mulher" ou a "pessoa ser escravo", condições estas que faziam com que a pessoa pudesse variar em grau de possibilidade social materializada na participação política reservada a "pessoa ser homem". Ou seja, o animal político aristotélico consistente na "pessoa completa" é uma pessoa do sexo masculino.

O pertencimento territorial é outro atributo que qualifica a pessoa na tradição filosófica clássica, identificado pela língua e demais elementos culturais que permitiam discernir o natural de uma localidade em relação à outra. Esta distinção muito utilizada fazia com que os gregos - e em momento posterior, os romanos - se diferenciassem dos bárbaros (DOUZINAS, 2009, p. 196). Então, a "pessoa completa" grega/romana era (1) natural de uma cidadeEstado grega/romana - na qual ela podia praticar política; e, (2) do sexo masculino ${ }^{6}$. Neste contexto, mulheres, escravos e estrangeiros

Do grego, significa "animal político".

Existiam outros requisitos para estar autorizado a ser um cidadão em Atenas, como maioridade ou mesmo ter cumprido o serviço militar entre outros. Especialmente à época da democracia, os requisitos eram mais estreitos, pois o campo participativo fora estendido com o legislador Clístenes. Seja como for, o artigo parte do pressuposto de que havia uma condição de pessoa que se diferenciava da outra, e quanto mais requisitos se exigisse para a participação 
Artigo original

Hegemonia - Revista Eletrônica de Relações Internacionais do Centro Universitário Unieuro

ISSN: $1809-1261$

UNIEURO, Brasília, número 15, 2015, pp. 17-41.

eram pessoas, mas não totalmente aptas a ser um animal político no sentido aristotélico. Em outras palavras, a "pessoa completa" se fazia pela dimensão política medida pelo sexo e pertencimento territorial.

Especificamente, a terminologia "humanidade" acompanhou esse processo iniciado na antiguidade. De origem latina, a palavra humanitas traduzia o termo grego paideia que significa educação. Conforme visto, a educação remete a cultura específica de uma localidade que era identificável através da língua distinguindo o grego de um bárbaro. O romano continuou esta tradição helênica com o humanitas": "O primeiro humanismo foi o resultado do encontro entre a civilização grega e a romana" (DOUZINAS, 2009, p. 196).

Com a consagração do cristianismo no período medieval, parte da tradição clássica se manteve com Santo Agostinho e Santo Tomás de Aquino, adeptos, respectivamente, de Platão e de Aristóteles (RUSSEL, 2004). Todavia, durante o medievalismo, os dogmas estabelecidos por Paulo de Tarso em suas epístolas de cunho evangelizador permearam o pensamento cristão em uma ideia inédita de acepção da pessoa em função da igualdade: "Uma concepção diferente de humanitas surgiu na teologia cristã", porém "esse universalismo espiritual foi acompanhado de uma rígida hierarquia política e social" (DOUZINAS, 2009, p. 196). Com o medievalismo se evidencia a humanidade abstrata em uma presunção de igualdade também abstrata, mas que em todo caso, permitia uma classificação da pessoa a partir de sua religiosidade ${ }^{8}$.

política que é o elemento diferencial de pessoa, maior se torna a força do argumento aqui exposto.

Importa destacar que o grego não utilizava a ideia de humano como critério diferencial de pessoa, tanto que a "palavra humanitas apareceu pela primeira vez na República Romana" (DOUZINAS, 2009, p. 196).

Por isto, judeus e mouros eram menos pessoas e não gozavam da igualdade plena na alma. O judeu conseguia ser pessoa à medida que abandonava sua crença e se tornava um "cristão novo". Na época das Cruzadas isto se fez ainda mais evidente, e os cruzados europeus mataram indistintamente qualquer outra 
Artigo original

Hegemonia - Revista Eletrônica de Relações Internacionais do Centro Universitário Unieuro

ISSN: $1809-1261$

UNIEURO, Brasília, número 15, 2015, pp. 17-41.

A condição de pessoa e de humanidade era dada pela aceitação religiosa e sua pretensão de igualdade que jamais se materializa, por isto inerente à abstração e associada à alma. A teologia cristã meditou sobre estas questões pelo nominalismo, que "vai reduzir a realidade a substâncias individuais" (VILLEY, 2007, p. 123). O surgimento do indivíduo remete ao nominalismo franciscano cujos expoentes são Duns Scotus e Guilherme de Ockham, sendo que, nessa base filosófica "a expressão máxima da criação é a individualidade" (DOUZINAS, 2009, p. 75).

O individualismo é a planta da concepção da pessoa na modernidade. Considerado o primeiro filósofo moderno (RUSSEL, 2004), René Descartes (1991, p. 46) é o arquiteto desta planta a partir de sua principiologia filosófica: "eu penso, logo existo, era tão firme e tão certa que (...) julguei que podia aceitá-la, sem escrúpulo, como o primeiro princípio da Filosofia que procurava". Tal princípio condensa e deriva a filosofia cartesiana em função da pessoa, a qual é protagonista do mundo pelo ato de pensar ${ }^{9}$. O escritor francês estipula que a pessoa é estabelecida pelo pensar e é sua própria essência que a permite "ser (...). De sorte que esse eu, isto é, a alma, pela qual sou o que sou, é inteiramente distinta do corpo" (DESCARTES, 1991, p. 47). Em outras palavras, ao precisar a existência da pessoa pela sua racionalidade em um espectro amplo denominado alma, Descartes ponderou que todas as pessoas são

pessoa que não fosse da religião católica, incluindo os cristãos que viviam sob o catolicismo ortodoxo ou os cristãos que viviam no território palestino. Vale consignar que o período medieval é marcado pela ausência de uma estrutura política que unifique a Europa Ocidental, então, a religião acaba fazendo este papel.

Interessante a diferença entre Descartes e Aristóteles, diferença esta que evidencia a mudança na concepção da pessoa na antiguidade e na modernidade. Enquanto Aristóteles atribuía à capacidade política a condição de pessoa, esta, para Descartes, se faz pela capacidade racional. 
Artigo original

Hegemonia - Revista Eletrônica de Relações Internacionais do Centro Universitário Unieuro

ISSN: 1809-1261

UNIEURO, Brasília, número 15, 2015, pp. 17-41.

racionais. Ao estabelecer a alma como o eu, o ser, a pessoa e alijá-la do corpo, da matéria, o que ele fez foi separar a pessoa do mundo a sua volta, quer dizer, separou sujeito de objeto.

A ideia medieval de que a pessoa se faz pela alma está presente em Descartes. Da mesma maneira, o indivíduo imaginado pela doutrina nominalista também compõe sua forma de pensar. Assim, Descartes "não apenas estabeleceu a certeza e a centralidade do sujeito, mas também transformou o mundo em um objeto, estabelecido a priori do sujeito como alvo de representação, cognição e intervenção" (DOUZINAS, 2009, p. 198). Com o isolamento do sujeito em relação ao objeto, a pessoa começa a se definir contraposta à natureza, nisto, não só o aspecto racional transparece nas relações entre sujeito e objeto, pois o sujeito, para além de sua racionalidade, é dotado também de pretensões individuais: o "poder da vontade é único; (...) obedece aos desejos e interesses do sujeito. Descartes o descreveu como o mesmo em nós e em Deus. A vontade moderna não conhece limites teóricos, mas apenas empíricos" (DOUZINAS, 2009, p. 200).

A cisão entre o sujeito e o objeto é o fundamento do paradigma filosófico que permite separar sujeito de objeto em um método científico de escopo objetivo. Todo conhecimento de mundo válido é inspirado nessa filosofia doutrinária cartesiana. "Após Descartes, a filosofia tornou-se uma meditação sobre o sujeito e sua relação com seu oposto, o objeto. (...) O mundo estava, assim, reduzido à sua representação (...) e o homem o centro de tudo o que existe" (DOUZINAS, 2009, p. 198-199). A epistemologia cartesiana do ser reflete o quadro moderno e a subelevação da racionalidade enquanto característica diferencial humana ${ }^{10}$. A ideia de humanidade passa a configurar como uma vertente da razão. Razão humana é o termo que redunda a condição da pessoa desde a modernidade.

Ao cunhar o termo homo sapiens - do latim, significa "homem sábio" - no século XVIII, o botânico sueco Carl Linnaues ratifica em sua taxonomia moderna a ideia já aceita a seu tempo de que a pessoa se diferencia dos outros seres pela racionalidade. 
Artigo original

Hegemonia - Revista Eletrônica de Relações Internacionais do Centro Universitário Unieuro

ISSN: $1809-1261$

UNIEURO, Brasília, número 15, 2015, pp. 17-41.

Muito embora o Renascimento italiano em seu nascedouro tenha preservado parte do humanismo antigo, "como um retorno aos protótipos grego e romano e era voltado ao barbarismo da escolástica medieval e do norte gótico" (DOUZINAS, 2009, p. 196), o desenvolvimento da modernidade rompeu com esse resgate da percepção greco-romana, motivado, sobretudo, pela filosofia política liberal. Mas, os filósofos liberais não romperam apenas com a perspectiva antiga de pessoa, como também com a humanidade religiosa, sendo que "a igualdade foi redefinida como política, em um processo que fortaleceu a tendência intelectual e a determinação popular de reconhecer a centralidade do indivíduo" (DOUZINAS, 2009, p. 196).

Hobbes (1974, p. 78) atesta a igualdade humana desde a natureza baseada na essência do indivíduo em tal estado. Não por acaso, Douzinas (2009, p. 87) afirma que a "antropologia natural de Hobbes é uma afirmação concisa da modernidade. (...) O sujeito é entronizado como um agente livre, como a origem imediata da atividade e da causa das ações que dele emanam". Ao estabelecer uma igualdade política desde a condição de natureza e formatar a sociedade a partir disto, Hobbes inverte não só o mecanismo social aristotélico vigente até então de se conceber a pessoa em comunidade, como também afirma a igualdade na esfera civil de convivência, algo inédito politicamente. Ademais, Hobbes (1974) inaugura a definição de "direito do homem"11 no capítulo XIV de Leviatã como a liberdade de cada homem de usar seu poder. Villey (2007, p. 142) destaca não saber se Hobbes foi o inventor do termo

Não é objeto deste trabalho identificar, pormenorizadamente, a ideia de "pessoa completa", humanidade e humano com a figura do homem, sexo masculino. Para uma crítica contundente sobre a fundamentação societal desde os contratualistas e seu comprometimento com a perspectiva masculina e solidificação do patriarcado liberal, ver Carole Pateman (1993). O artigo considera as críticas de Pateman no sentido de que a composição do conceito de humanidade parte da figura masculina a qual arroga para si o título de humano em detrimento da condição da mulher. 
Artigo original

Hegemonia - Revista Eletrônica de Relações Internacionais do Centro Universitário Unieuro

ISSN: 1809-1261

UNIEURO, Brasília, número 15, 2015, pp. 17-41.

"direito do homem", porém "em sua obra aparecem em plena luz suas fontes, seu conteúdo e sua função original".

Ao firmar a condição da pessoa de acordo com a individualidade em contraposição a dimensão social, Hobbes afirma os direitos fundamentados desde o indivíduo: "impregnado da lógica de Guilherme de Ockham, partidário do nominalismo, nela só encontrará indivíduos, mas providos de uma 'natureza' comum; naturalmente iguais e livres, subtraídos a qualquer hierarquia" (VILLEY, 2007, p. 145). O humano hobbesiano partilha dos direitos do homem, inaugurando as premissas de direitos humanos. Mas, o humano de Hobbes é um ser isolado cujo artifício é se legitimar juridicamente a partir de si próprio contrapondo-se ao mundo, inclusive à própria sociedade, isto é, o direito humano em Hobbes nasce em detrimento da comunidade. A única limitação do direito humano de Hobbes é o "limite do interior, da Razão subjetiva do indivíduo. Toda liberdade é, por essência, indeterminada, infinita. Esse é o direito que Hobbes reconhece pertencer a todos os homens" (VILLEY, 2007, p. 147).

Os escritos de Hobbes viabilizam a ideia de indivíduo no âmago político-jurídico. Conforme preceitua Bobbio (1998), o liberalismo não teria surgido sem o individualismo. É nesse sentido que Douzinas (2013) elege Hobbes como o primeiro liberal. Deste modo, Locke não representa uma ruptura com o modelo antropológico hobbesiano e seu entendimento sobre a pessoa. Aliás, Locke aproveita sua metodologia sociológica para averiguar estado de natureza, pacto e formação da sociedade política. A diferença fundamental é quanto à base jurídica aportada em Locke (1983, p. 45) na propriedade: "cada homem tem uma propriedade em sua própria pessoa; a esta ninguém tem qualquer direito senão ele mesmo. O trabalho do seu corpo e a obra de suas mãos, pode dizer-se, são propriamente dele".

A propriedade em Locke é vista como um direito do homem, e, nesse viés, um direito correlato à humanidade. A extensão desse direito é medida pelo trabalho e a capacidade de usufruir dos frutos do mesmo. Mas, com o dinheiro, o homem pôde converter seu trabalho em termos monetários e ampliar suas propriedades (LOCKE, 1983 , p. 46-54). Locke substitui o direito à liberdade total e ilimitada do estado de natureza por propriedades: "propriedade, no sentido 
Artigo original

Hegemonia - Revista Eletrônica de Relações Internacionais do Centro Universitário Unieuro

ISSN: 1809-1261

UNIEURO, Brasília, número 15, 2015, pp. 17-41.

lato, inclui todo direito individual. Ela é o que é meu e como tal deve ser-me atribuído (suum cuique tribuendem ${ }^{12}$ ) como coisa particular em relação aos outros, e do que os outros estão excluídos. Sinônimo de direito" (VILLEY, 2007, p. 152-153).

Com a supremacia da filosofia liberal e a ampla aceitação de Locke, sua teoria dos direitos do homem se torna a base jurídica exemplar e "conheceu um imenso sucesso histórico" (VILLEY, 2007, p. 154). Por isto, todos os direitos posteriores derivam do direito de propriedade (DOUZINAS, 2013, p. 85). Neste ponto, voltamos a Descartes em sua operação sujeito e objeto, sendo que, por intermédio de Locke, o direito se tornou uma relação exclusivamente entre sujeito (indivíduo) e objeto (propriedade). O direito humano reproduz esse cenário a partir de um humano que se tornou sujeito dos objetos com o advento da modernidade. Mas, é em Kant que se sacramenta a ideia de humanidade moderna presente nos direitos humanos contemporâneos, pois se trata da "mais avançada e ainda insuperada defesa inicial da centralidade do sujeito e da normatividade da humanidade" (DOUZINAS, 2009, p. 193).

A teoria kantiana reflete a época do século das luzes. A perspectiva de progresso infinito tendo em vista a racionalidade humana chega ao seu apogeu ao final do século XVIII, sendo que "o conceito de 'homem' havia se tornado o valor absoluto e inalienável em torno do qual o mundo todo girava" (DOUZINAS, 2009, p. 196). O Iluminismo adentrou o século XIX como uma forma influente de disseminar valores e tendências, especialmente no campo científico (GRAY, 2004). Aliás, Kant faz uma resenha do que seja a Ilustração palavra que corresponde ao Iluminismo - em termos de racionalidade, como se fosse um amadurecimento da pessoa, do homem. Atribui à "preguiça e covardia" a permanência em um estado irracional, como se fosse uma "menoridade". Kant vai além ao afirmar que passar à "maioridade" é algo difícil não só para a maior parte da humanidade, mas também para "todo o belo sexo". No eixo kantiano, a Ilustração

Do latim, significa "dar a cada um o que é seu". 
Artigo original

Hegemonia - Revista Eletrônica de Relações Internacionais do Centro Universitário Unieuro

ISSN: $1809-1261$

UNIEURO, Brasília, número 15, 2015, pp. 17-41.

é o esclarecimento humano pela razão, sendo que o requisito é a liberdade, "a saber: a de fazer uso público de sua razão em todas as questões" (KANT, 2005, p. 65).

Porém, é na "Fundamentação da Metafísica dos Costumes", escrito em 1785, que Immanuel Kant vai detalhar as questões relativas ao sujeito em uma acepção autonômica. A autonomia ${ }^{13}$ e a liberdade perfazem uma conjuntura que alia completamente racionalidade e vontade: "todo o ser racional deve considerar-se como legislador universal por todas as máximas da sua vontade para, deste ponto de vista, se julgar a si mesmo e às suas ações" (KANT, 2007, p. 75). O resultado deste diagnóstico kantiano representa o ápice do controle do sujeito sobre o objeto, sendo que a "consciência e a vontade modernas tornam-se legislativas: sujeitos agora podem examinar as regras por si próprios e podem rejeitá-las e substituí-las" (DOUZINAS, 2009, p. 200-201). A ausência de limitação ao indivíduo passa a conferir o desenho atômico ${ }^{14}$ da autonomia que desemboca na moralidade, a qual "é pois a relação das ações com a autonomia da vontade, isto é, com a legislação universal possível por meio das suas máximas" (KANT, 2007, p. 84).

Em contraposição à autonomia, Kant trabalha com o conceito de heteronomia, que ética e filosoficamente está enraizado na ideia de submissão. No primeiro caso, os princípios racionais derivam da perfeição e do conceito de racionalidade sendo o próprio imperativo moral ou categórico na perspectiva em que a vontade busca a lei a partir de sua máxima intrínseca. Por outro lado, os princípios empíricos derivam da felicidade provêm da dimensão física, sendo o imperativo categórico que é condicionado. Neste último caso, "um objeto da vontade tem de ser posto como fundamento para prescrever a essa vontade" (KANT, 2007, p. 90).

Hegel projeta sua crítica radical a Kant motivado, em parte, pela ideia de sujeito atômico e os desdobramentos sociais desta visão. Este ainda é um dos grandes debates da teoria social contemporânea, evidenciada em dicotomias tais como "agência $x$ estrutura", "indivíduo $x$ instituição", "subjetividade $x$ intersubjetividade", entre outras. 
Artigo original

Hegemonia - Revista Eletrônica de Relações Internacionais do Centro Universitário Unieuro

ISSN: 1809-1261

UNIEURO, Brasília, número 15, 2015, pp. 17-41.

O que une o sujeito ao objeto é a razão (DOUZINAS, 2009, p. 201). Todavia, a razão é o diferencial do sujeito, constituído a partir de si mesmo, ou seja, o objeto passa a ser o que o sujeito deseja que seja. Nessa "revolução epistemológica de Kant", a "verdade originase e existe no homem e, como consequência de sua revolução cognitiva, a completa compreensão e o domínio do mundo tornam-se possíveis" (DOUZINAS, 2009, p. 199). O arranjo kantiano da razão inverte a perspectiva de mundo, o qual se faz a partir do ser e sua conviç̧ão, sendo que uma lei universal abstrata a partir da racionalidade é engendrada assepticamente à realidade as noções prévias de bem e de mal. É a própria fórmula do imperativo categórico: "Age segundo a máxima que possa simultaneamente fazer-se a si mesma lei universal" (KANT, 2007, p. 80). Esta operação lógico-filosófica inverte o local da lei, a qual antecede o mundo e a experiência sensível do sujeito, é a "lei moral que define o bem e o mal" (DOUZINAS, 2009, p. 202).

O objetivo deste tópico é demonstrar que o conceito de humanidade o qual legitima os direitos humanos não é atemporal ${ }^{15}$, possuindo cargas axiológicas a partir de si mesmo que justifique a proclamação da dignidade humana como fundamento jurídico supremo. A própria ideia de natureza e a relação da pessoa com esta foi profundamente alterada na modernidade, e é isto que permitiu uma percepção inovadora da pessoa: "Para Hobbes ou Locke, Descartes ou Voltaire, os homens compartilham uma humanidade comum que confere a todos os homens empíricos as mesmas necessidades e características essenciais, muito embora seu conteúdo específico difira de acordo com o teórico" (DOUZINAS, 2009, p. 206). Esta humanidade comum está na supremacia do sujeito em relação ao objeto, na presunção de que o humano controla a natureza.

Sobre isto, Douzinas (2009, p. 250) destaca que o "humanismo jurídico postulou o homem como o autor e o fim da lei e culminou na ideia dos direitos humanos. Mas, quando os direitos humanos minam a distinção entre o real e o ideal, eles se transformam no alicerce do historicismo moderno". 
Artigo original

Hegemonia - Revista Eletrônica de Relações Internacionais do Centro Universitário Unieuro

ISSN: 1809-1261

UNIEURO, Brasília, número 15, 2015, pp. 17-41.

A natureza em diversas culturas e sociedades é algo muito além da pessoa e qualquer imaginação de controle ou domínio sobre a mesma $^{16}$. O posicionamento do humano acima da natureza retira de si a própria natureza humana enquanto algo natural para inventá-la desde si em um processo metafísico que "cria mundo ideais, unificados e logicamente harmoniosos e denomina-os realidade" (DOUZINAS, 2009, p. 212). Esta realidade abstrata e fictícia se compõe em um axioma, um ponto hermético que produz seu próprio funcionamento, por isto Douzinas $(2009$, p. 206) ressalta que a "pessoa é uma aplicação individual do homem universal; a essência humana vem antes da existência".

O resultado é a divergência humana da realidade fática apoiada no parecer moral kantiano que dita o ritmo das supostas verdades universais. Quer dizer que a humanidade se liberta de qualquer elemento que a possa condicionar, seja de ordem histórica, cultural, política ou social. De acordo com Douzinas (2009, p. 208-209), isto estabelece 0 nada ${ }^{17}$ da natureza humana. A filosofia dos direitos humanos segue essa linha desde Kant e seu prognóstico de humano enquanto sujeito dotado de autonomia para estabelecer a lei moral universal do mundo. Mas, isto tem consequências políticas e jurídicas profundas que serão exploradas na sequência. Antes, contudo, segue uma crítica à modernidade kantiana.

Sobre esta questão, os gregos atribuem à tentativa de a pessoa controlar a natureza através da técnica, mas esta é sempre incontrolável (DOUZINAS, 2013). A própria tragédia de Antígona escrita por Sófocles representa alegoricamente este debate entre a natureza e a pessoa. Culturas orientais como hinduísmo, budismo e confucionismo pregam, antes de tudo, equilíbrio entre pessoa e o mundo que lhe cerca que é a natureza. Religiões de matrizes africanas como o candomblé partem desse mesmo pressuposto harmônico. A modernidade rompeu com toda esta tradição filosófica.

Douzinas (2009, p. 205-201) aponta Sartre como o precursor desta crítica niilista à natureza humana presente em Descartes e Kant. Ademais, o autor grego arrola Burke e Marx como críticos pioneiros dos direitos humanos em suas vertentes abstratas, universalistas e sem determinação. 
Artigo original

Hegemonia - Revista Eletrônica de Relações Internacionais do Centro Universitário Unieuro

ISSN: $1809-1261$

UNIEURO, Brasília, número 15, 2015, pp. 17-41.

\section{Qual modernidade?}

A modernidade não é um conceito pleno e acabado, pelo contrário, trata-se de um conceito em aberto e mais, em disputa ${ }^{18}$. $O$ conceito de modernidade na perspectiva majoritária guarda uma promessa de emancipação que será conquistada à medida que a modernidade for completada enquanto projeto. Esta visão é contemporânea e encontra Habermas (2011) como adepto.

Conforme pontua Habermas (apud DUSSEL, 1993, p. 23): "os acontecimentos históricos-chave para a implantação do princípio da subjetividade são a Reforma, a Ilustração e a Revolução Francesa". A constatação habermasiana sobre a modernidade evidencia uma construção a partir de eventos exclusivamente europeus e constitui o mainstream analítico da ciência social estabelecido em uma visão eurocêntrica adotada pelos Estados Unidos da América, endossando um discurso hegemônico de modernidade etnocêntrica, a qual afirma e reproduz uma modernidade de sentido unilateral. Obviamente que a modernidade de Habermas remete a uma filosofia mais antiga de escopo eurocêntrico.

O eurocentrismo é "uma perspectiva de conhecimento cuja elaboração sistemática começou na Europa Ocidental antes de mediados do século XVII" (QUIJANO, 2005, p. 236). É uma produção de verdade que tem relação direta na consolidação do poder sobre o ser $^{19}$. Apesar de suas origens anteriores ao século XVII, o

Em termos didáticos, a modernidade é classificada como um fenômeno da Idade Moderna iniciada em $1453 \mathrm{com}$ a Queda de Constantinopla. Autores europeus como Kant e Hegel estipulam a modernidade como um movimento exclusivamente europeu. Dussel (1993) questiona essa posição ao inserir a América Latina no processo.

Este efeito é similar às análises de Foucault (2005), porém "o que Foucault não conseguiu capturar em sua denúncia foi o eurocentrismo e o colonialismo" (BALLESTRIN, 2013, p. 103). 
Artigo original

Hegemonia - Revista Eletrônica de Relações Internacionais do Centro Universitário Unieuro

ISSN: 1809-1261

UNIEURO, Brasília, número 15, 2015, pp. 17-41.

eurocentrismo tem sua fundamentação mais rebuscada construída sob a orientação iluminista, muito presente em Kant, mas com requintes de sofisticação em Hegel.

A Ilustração kantiana "é a saída por si mesma da humanidade de um estado de imaturidade culpável" (KANT apud DUSSEL, 1993, p. 17). Desde essa assertiva, Dussel questiona se os povos subjugados pela modernidade são os responsáveis por sua condição de oprimidos. É a filosofia da história hegeliana ${ }^{20}$ que tem a resposta para o questionamento de Dussel quanto à responsabilidade desses povos não-modernos, imaturos: "A história universal representa... O desenvolvimento da consciência que o Espírito tem de sua liberdade e também a evolução da realização que esta obtém por meio de tal consciência" (HEGEL apud DUSSEL, 1993, p. 18).

O desenvolvimento é a peça chave para compreender essa responsabilidade, sendo uma lógica dialeticamente linear em uma direção no espaço: "A história universal vai do Oriente para o Ocidente. A Europa é absolutamente o fim da história. A Ásia é o começo" (HEGEL apud DUSSEL, 1993, p. 18). Para constituir sua evolução histórica, Hegel precisou eliminar de sua história universal a América Latina e a África. Sobre a América (Latina), o filósofo de Stuttgart a projeta para o futuro ao dizer que o local não terminou sua formação e conclui que não cabe à filosofia fazer profecias. Quanto à África, a sentença hegeliana é de que se trata de um lugar fechado em que a consciência não foi despertada para nenhuma objetividade; seu diagnóstico final sobre a África é que "é algo isolado e sem história, sumido ainda por completo no espírito natural" (HEGEL apud DUSSEL, 1993, p. 19-20).

A modernidade em Hegel assume seu eurocentrismo cabal no mundo germânico e se inicia na Reforma Luterana, se desenvolvendo no Iluminismo e na Revolução Francesa até culminar na missão civilizatória inglesa: "os ingleses decidiram se transformar nos

Apesar de Hegel se contrapor filosoficamente a Kant, em termos de Iluminismo, suas abordagens coincidem. 
Artigo original

Hegemonia - Revista Eletrônica de Relações Internacionais do Centro Universitário Unieuro

ISSN: 1809-1261

UNIEURO, Brasília, número 15, 2015, pp. 17-41.

missionários da civilização em todo o mundo" (HEGEL apud DUSSEL, 1993 , p. 22). Os detentores da modernidade nessa preceituação eurocêntrica são a Alemanha e a Inglaterra, ou seja, a Europa hegeliana: o povo do Norte que "tem assim um 'direito absoluto' por ser o 'portador' do Espírito neste 'momento de seu Desenvolvimento'. Diante de cujo povo todo outro-povo 'não tem direito'" (DUSSEL, 1993, p. 22).

A - e o direito à - colonização adquire uma função de superar as contradições da sociedade civil absorvendo o vestígio negativo do capitalismo: "a 'periferia' da Europa serve assim de 'espaço livre' para que os pobres, fruto do capitalismo, possam se tornar proprietários, capitalistas nas colônias" (DUSSEL, 1993, p. 23). Hegel é o paladino da superioridade europeia em sua caracterização mais acentuada, conferindo as armas ideológicas à Europa Ocidental e estabelecendo a modernidade como um processo eurocêntrico em uma postura etnocêntrica. Os Estados Unidos da América assimilaram esse pensamento manipulando-o aos seus objetivos em uma proeminência do Atlântico Norte compartilhado entre os países desse eixo.

Assim, a colonização é o processo etnocêntrico em que o europeu busca diferenciar-se como "raça" superior ou no último estágio da "civilização" (DUSSEL, 1993, p. 22). Desta forma, a missão do europeu a partir da modernidade é "civilizatória", e para tal missão qualquer ato é justificável. Os habitantes originários das Américas foram "inventados" (DUSSEL, 1993, p. 32) pelo europeu como índio, como "ser asiático". Em seguida o europeu percebeu que não se tratava de um "ser conhecido", mas um "novo ser" em um "Novo Mundo": eis o "descobrimento" da América. Da "descoberta" passou-se a "conquista" em atos de guerra e, finalmente, a "colonização" (DUSSEL, 1993, p. 34-50). Esta última se desdobrou em "conquista espiritual" traduzindo o "mito civilizador" (DUSSEL, 1993, p. 58-60), sendo que todo o processo racionalizado de violência característico da colonização passou a ser mitigado pela expectativa de um "encontro" de dois mundos (DUSSEL, 1993, p. 64).

As relações entre americanos e europeus não foram um "encontro de culturas" (DUSSEL, 1993, p. 65), mas sim o "encobrimento do outro"; no caso, o europeu impôs de forma 
Artigo original

Hegemonia - Revista Eletrônica de Relações Internacionais do Centro Universitário Unieuro

ISSN: 1809-1261

UNIEURO, Brasília, número 15, 2015, pp. 17-41.

assimétrica suas verdades, concepções, doutrinas e dogmas concebidos sob o argumento da "civilização". O "outro" no contexto da América Latina é todo ser humano não-europeu. Todo aquele que não tem o atestado de humanidade europeia é considerado aquém da cultura, como "incivilizado". O "encobrimento" típico da colonização europeia foi extenso: a desestruturação do "aparato cultural e simbólico das populações autóctones da América, advindo entre elas um sentimento de desreferencialização do mundo" (DUSSEL, 1993, p. 67).

O "encobrimento", portanto, é uma destruição cultural profunda das referências basilares dos povos originários da América. Este fenômeno do "encobrimento" no processo de colonização "é um processo de racionalização próprio da modernidade: elabora um mito de sua bondade ('mito civilizador') com o qual justifica a violência e se declara inocente pelo assassinato do Outro" (DUSSEL, 1993, p. 58-59). Eis a resposta de Hegel a indagação de Dussel quanto à responsabilidade dos povos subjugados estabelecida por Kant: uma transferência da culpa pelo seu próprio atraso que justifica qualquer ato em nome da razão moderna europeia. Essa é a modernidade que ainda vigora na teoria e na filosofia dos direitos humanos.

O conceito moderno de humanidade que fundamenta os direitos humanos é uma abstração que se pretende universal de uma pessoa do sexo masculino, branca, de cultura europeia ocidental, dotada de uma razão unilateral. Ser humano requer se adaptar a estes atributos conceituais. O dogma da racionalidade como critério diferencial da pessoa inaugurado por Descartes perpassa por toda a modernidade encontrando Kant seu maior exponencial filosófico. A partir de Kant, a razão passa a ser o arcabouço de toda a modernidade. Os autores destacados no bojo do artigo compartilham desta tradição filosófica, a qual permanece em Weber e Habermas, dois autores adeptos da doutrina liberal kantiana. A racionalidade é uma exigência para a modernidade, e todo aquele que não se encontra na plena razão iluminista é algo menos que o humano do tipo ideal, e seus direitos, inclusive os direitos humanos, estão condicionados à aceitação da modernidade baseada na racionalidade. 
Artigo original

Hegemonia - Revista Eletrônica de Relações Internacionais do Centro Universitário Unieuro

ISSN: 1809-1261

UNIEURO, Brasília, número 15, 2015, pp. 17-41.

3. O esvaziamento político dos direitos humanos na dupla acepção do sujeito

Ao pressupor a pessoa em uma máxima atômica projetada no sentido unilateral do sujeito, a "autonomia kantiana torna o homem moderno o sujeito da lei em um duplo sentido: ele é o legislador, o sujeito que provê a lei, e o sujeito jurídico, sujeitado à lei na condição de que participou de sua legislação" (DOUZINAS, 2009, p. 203). A posição do humano perante o mundo o torna, ficticiamente, senhor deste mundo, mas, por outro lado, cria suas próprias barreiras que significam sujeição, e nesta ambiguidade essencial se constrói e se reconstrói o sujeito jurídico, o mesmo sujeito dos direitos humanos (DOUZINAS, 2009, p. 225).

Etimologicamente, a palavra sujeito provém de duas palavras de origem latina cujos significados são contrários: subjectum e subjectus. Enquanto subjectum configura no polo ativo da faceta humana, o subjectus está no polo passivo desta. De certa forma, isto condiz com a sociedade moderna em suas pretensões políticas e teóricas de condicionar a liberdade do agente humano (DOUZINAS, 2009, p. 226). Esta inovação jurídica dicotômica está presente no direito contemporâneo desde a Revolução Francesa ${ }^{21}$, a qual é considerada um marco histórico ${ }^{22}$ para os direitos humanos.

A Revolução Francesa, aliás, se propugnou como um ato de resistência ao poder político de então baseado no absolutismo. Os fundamentos teóricos revolucionários pressupunham o direito de

A Revolução Francesa é um divisor de águas na História Contemporânea, e a influência da mesma para o mundo ocidental é enorme. Nesse sentido, Eric Hobsbawn destaca que a "ideologia do mundo moderno (...) foi obra da Revolução Francesa" (1977, p. 84), portanto, é natural atrelar a história dos direitos humanos à Revolução de 1789 em França.

Sobre toda a trajetória evolutiva do desenvolvimento do sujeito no conceito de humanidade, ver Douzinas (2009, p. 227-229). 
Artigo original

Hegemonia - Revista Eletrônica de Relações Internacionais do Centro Universitário Unieuro

ISSN: 1809-1261

UNIEURO, Brasília, número 15, 2015, pp. 17-41.

resistir tendo em vista a liberdade e igualdade humanas. Mas, ancorados no idealismo alemão kantiano, os desdobramentos da Revolução Francesa excluíram de seus quadros normativos qualquer ideia de resistência que pudesse colocar em risco a ordem estabelecida (DOUZINAS, 2013, p. 82-83). Mais do que isto, abandonaram a resistência em preferência a uma liberdade/igualdade vazia e formal, que evidenciava toda a carga abstrata de uma humanidade universal, sobretudo quando se contrapunha ao próprio desfecho da Revolução Francesa que não garantia sequer a igualdade formal às mulheres e aos que não eram brancos (DOUZINAS, 2009, p. 229).

Os direitos humanos partem da hipótese de um humano livre e igual para reivindicar sua própria dignidade. Por tratar o humano como hipótese dada e aceita, os direitos humanos formulam condições jurídicas imaginárias e impraticáveis, afetando qualquer perspectiva de realização e efetivação. Epistemologicamente, a dignidade se estranha entre objeto e sujeito, não se definindo politicamente, para ao final se tornar o fundamento do direito presumido do humano. Isto acontece porque o sujeito em sua dimensão sujeitada é, na realidade, objeto jurídico, todavia, após os trâmites da Revolução Francesa, "o subjectus tornou-se cidadão e deu início à sua jornada em direção a tornar-se o sujeito moderno livre e autônomo" (DOUZINAS, 2009, p. 230). A parte ativa do sujeito, o subjetum revolucionário que resistiu ao absolutismo, foi alijada da política e desalojada do resguardo jurídico dado seu risco potencial à nova ordem que se estabelecia.

A política atual contemporiza a sujeição em direitos, como se estes fossem além do poder, o qual "tornou-se o objeto de um discurso jurídico, que colocava os direitos humanos, com o frágil conceito de homem, no seu centro e segundo o qual o poder deve agora justificar o seu exercício" (DOUZINAS, 2009, p. 230). Assim, as democracias contemporâneas abrigam a humanidade alicerçada na igualdade formal e jurídica não como ponto de chegada, mas como ponto de partida e condição para a realização democrática. Nesta esteira, os direitos humanos configuram como garantes de uma humanidade estanque que não tem relações políticas, mas apenas 
Artigo original

Hegemonia - Revista Eletrônica de Relações Internacionais do Centro Universitário Unieuro

ISSN: 1809-1261

UNIEURO, Brasília, número 15, 2015, pp. 17-41.

uma normatividade ideal que pretende resolver por si mesma os problemas sociais, desde os mais rasos até os mais graves, daqueles locais aos mundiais.

Os direitos humanos estabelecidos como norma universal aplicável a todo o mundo são o resultado do processo histórico e filosófico da construção do conceito moderno de humanidade e seus desdobramentos teoréticos. A prática jurídica do humano que desenvolveu o sujeito do direito na dupla acepção, descrita anteriormente, demonstra que não há um limite para o que pode ser contemplado pelo direito, nem a título de sujeito, nem a título de objeto. Desta maneira, não há qualquer limitação para a pretensão universal do tratamento humano dado ao mundo e à natureza, em que o critério para se tornar direito humano, seja sujeito, seja objeto, é a própria perspectiva de humanidade a partir de si mesmo, por esta razão Douzinas (2009, p. 253) afirma que "os direitos humanos tornaram-se a expressão máxima da moralidade da lei, da política governamental e das decisões internacionais". Em uma assertiva trivial: tudo se transformou e se transforma em direitos humanos. $O$ paradigma que se estabelece a partir disto é a totalização dos direitos humanos, em que tudo pode se tornar sujeito de direito - e objeto.

Para além de uma pessoa, animais e natureza também têm sido reconhecidos como sujeitos de direitos. No mesmo diapasão, empresas e demais pessoas jurídicas idem. Aliás, a própria definição de pessoa jurídica é parte deste conceito abstrato de sujeito reflexo da humanidade. Por outro lado, as pessoas também podem virar objetos das relações jurídicas, a serem tutelados, cuidados, vigiados, a depender da área jurídica, pois o "potencial criativo da linguagem e da retórica permite aos direitos originais do 'homem' fragmentaremse e proliferarem nos direitos dos vários tipos de sujeito" (DOUZINAS, 2009 , p. 262). A conquista de um direito ajuda a incrementar a lógica de expansão jurídica. Ao lutar pelo reconhecimento ${ }^{23}$ de uma

Axel Honneth (2003) é um dos expoentes da teoria do reconhecimento contemporâneo em que um dos pontos centrais é o alargamento do escopo jurídico pela ética societal. Douzinas (2009, p. 279-286) tece duras críticas a esta visão normativa de sociedade exposta por Honneth. 
Artigo original

Hegemonia - Revista Eletrônica de Relações Internacionais do Centro Universitário Unieuro

ISSN: $1809-1261$

UNIEURO, Brasília, número 15, 2015, pp. 17-41.

determinada reivindicação e tê-la normatizada, o horizonte do direito se expande. Concomitantemente, abre-se espaço para novas pretensões. À medida que se atende novas pretensões, o escopo jurídico vai sendo ampliado. Por óbvio que esta dilatação sem precedentes tem tido sua repercussão política ao não efetivar o direito, pois sua meta subjetiva não encontra limites além da própria subjetividade que se manifesta como a legalização do desejo (DOUZINAS, 2009, p. 268).

Histórica e filosoficamente, porém, o direito não é percebido como uma entidade totalizante. Pelo contrário, o direito tem uma função bastante específica no sentido de compor conflitos. A máxima romana ubi societa ibi ius ${ }^{24}$ reafirma a missão precípua do direito em termos práticos de estar presente em sociedade. Mais do que isso, desde o brocardo romano o direito é percebido como algo social e não uma abstração a partir do indivíduo, quanto menos uma pretensão geral e universal de humano total a partir do jurídico. Considerando o conflito como parte da sociedade ${ }^{25}$, em uma perspectiva genérica, é razoável conceber o direito como uma técnica para resolver o mesmo. O problema é que o direito moderno na sua evolução para direitos humanos, tendo em vista o sujeito humano que tudo regulamenta a partir de si, tende a estipular as normas do conflito, o que acentua tal fenômeno e não o resolve: "a apresentação do conflito em termos de direitos não ajuda e poderia retardar ainda mais a sua resolução" (DOUZINAS, 2009, p. 258).

Do latim, significa que "onde está a sociedade, está o direito".

Honneth (2003) estabelece uma teoria social de teor normativo a partir de Hegel e sua categoria de reconhecimento que pressupõe o conflito. No caso, Hegel resgata a intersubjetividade nas relações sociais inspirado nos gregos, em especial Heráclito (RUSSEL, 2004), o qual enxergava o conflito desde a natureza. 
Artigo original

Hegemonia - Revista Eletrônica de Relações Internacionais do Centro Universitário Unieuro

ISSN: $1809-1261$

UNIEURO, Brasília, número 15, 2015, pp. 17-41.

Além disso, ao enquadrar o conflito social como norma, os direitos humanos o reduzem a um escopo constituído dotado de ideais e ideias prévias, juízos de valor e cargas axiológicas que nem sempre correspondem à situação fática do conflito. A isto se agrega a operação jurídica baseada no direito de propriedade em que apenas um polo da relação tem sua pretensão satisfeita, em um resultado que jamais atinge um mínimo de equilíbrio. O tudo contra o nada da lógica jurídica faz com que o conflito seja descaracterizado. Ademais, o processamento do litígio se faz por narrativas recheadas de estigmas interpretativos que escancaram um discurso vazio, "devido, em parte, à sua linguagem, que se tornou tão ampla, abstrata e engloba tudo, a ponto de poder ser empregada em todos os tipos de conflitos políticos e sociais para proporcionar legitimidade moral a qualquer interesse e reivindicação, do mais sério ao mais trivial" (DOUZINAS, 2009, p. 259).

O que permitiu o conceito moderno de humanidade, conforme visto, foi o critério da razão. Mas a razão não pode ser um critério universal para oferecer todas as respostas aos problemas, quanto mais àqueles decorrentes da sociedade que se materializam em conflitos políticos. Ademais, a formatação da razão teve uma historicidade ligada à modernidade europeia e etnocêntrica que excluiu os demais humanos do mundo, pois a humanidade moderna kantiana tem forma e se apega a esta, desdobrando-a em detrimento da realidade. Neste sentido, "as principais oposições da jurisprudência da modernidade foram inauguradas por Kant: legalidade e moralidade, forma e conteúdo, validade e valor, norma e fato" (DOUZINAS, 2009, p. 204). Todavia, como a verdade universal baseia-se no entendimento humano e sua vontade vinculada à autonomia, moralidade, conteúdo, valor e fato, ou seja, todos os requisitos que se pretendem materiais transitam do objeto para a subjetividade do sujeito, tornando todo o direito uma questão de forma, por isto o formalismo jurídico se afirma perante a matéria, inclusive nos direitos humanos.

Douzinas (2011, p. 3) estabelece que "o objetivo dos direitos humanos é de resistir à dominação e à opressão pública e privada". Ao refletir sobre a crise atual na Grécia, o autor grego restabelece a 
Artigo original

Hegemonia - Revista Eletrônica de Relações Internacionais do Centro Universitário Unieuro

ISSN: 1809-1261

UNIEURO, Brasília, número 15, 2015, pp. 17-41.

resistência filosoficamente como um direito que fora alijado pela doutrina kantiana após a Revolução Francesa e que isto reflete nos tratados internacionais contemporâneos de direitos humanos (2013, p. 83). Especialmente nas relações públicas, em que o Estado consubstancia-se legitimado em uma ordem imposta, é que os direitos humanos na categoria de resistência se fazem mais evidentes e importantes, sobretudo nas situações relacionais assimétricas (SANTANDER, 2011, p. 2). Na seara dos direitos humanos consignados pelo humanismo jurídico, o esvaziamento do sentido político atinge seu apogeu oficial, pois quando o "Estado reconhece os direitos humanos e os sistematizam através do direito (tipificação), inverte-se o polo de legitimidade da ação. A ação legítima passa a ser a do Estado, e não mais a das pessoas negligenciadas. A normatividade trabalha em detrimento da parte hipossuficiente" (SANTANDER; RIBEIRO, 2014, p. 279).

O direito em sua manifestação normativa não é um fenômeno desvinculado da política e de seus efeitos. Pelo contrário, continuam tendo um poder inexorável sobre as relações sociais. Não por acaso Douzinas (2009, p. 268) afirma que os "direitos são ficções extremamente poderosas cujo efeito sobre as pessoas e as coisas é profundo: eles fazem as pessoas sacrificarem sua vida ou sua liberdade, eles levam as pessoas a matar ou mutilar em seu nome, eles inspiram as pessoas a protestar, a se rebelar e a mudar 0 mundo". O esvaziamento político dos direitos humanos tem sido uma prova cabal deste efeito do excesso de normatividade a partir do conceito moderno de humanidade em sua proposição ambígua da pessoa sujeito e sujeitado.

Considerações finais

O artigo buscou resgatar os efeitos políticos do conceito moderno de humanidade, mais especificamente relacionando com o esvaziamento político dos direitos humanos em sua ideia básica de resistência. Não se trata de um ataque vazio aos direitos humanos, os quais são uma conquista, uma meta e uma importante ferramenta 
Artigo original

Hegemonia - Revista Eletrônica de Relações Internacionais do Centro Universitário Unieuro

ISSN: $1809-1261$

UNIEURO, Brasília, número 15, 2015, pp. 17-41.

contemporânea na defesa da pessoa. Todavia, o que se pretende com esta crítica é contemporizar o caráter inacabado dos direitos, os quais sempre precisam ser revistos e redimensionados para que seu tato com a realidade não seja perdido, pois a busca por efetividade e eficácia ainda é a luta fundamental dos direitos humanos.

Referências bibliográficas

ARISTÓTELES. A Política. São Paulo: Lafonte, 2012.

BALLESTRIN, Luciana. América Latina e o giro decolonial. Revista Brasileira de Ciência Política, v. 2, p. 89-117, 2013.

BOBBIO, Norberto. Liberalismo e democracia. 6. ed. São Paulo: Brasiliense, 1998.

DESCARTES, René. Discurso do método. Trad. do francês por J. Guinsberg e Bento Prado Jr. 5. Ed. São Paulo: Nova Cultural, 1991. DOUZINAS, Costas. Philosophy and resistance in the crisis - Greece and the future of Europe. Cambridge: Polity, 2013.

. O fim dos direitos humanos. São Leopoldo: Unisinos, 2009. . O paradoxo dos direitos humanos. In: Pensar os direitos humanos: desafios à educação nas sociedades democráticas. v. $1 \mathrm{n}$. $1,2011$.

DUSSEL, Enrique. 1492: o encobrimento do outro: a origem do mito da modernidade: Conferência de Frankfurt. Petrópolis: Vozes, 1993.

FOUCAULT, Michel. Microfísica do Poder. $21^{a}$ ed. Rio de Janeiro: Edições Graal, 2005.

GRAY, John. Al-Qaeda e o que significa ser moderno. Trad. De Maria Beatriz de Medina. Rio de Janeiro: Record, 2004.

HOBBES, Thomas. Do Cidadão. São Paulo: Editora Martin Claret, 2003.

. O Leviatã. São Paulo: Abril Cultural, 1974.

HONNETH, Axel. Luta por reconhecimento: a gramática moral dos conflitos sociais. 2a ed. São Paulo: Ed. 34, 2003.

HOBSBAWN, Eric J. A Era das revoluções: Europa 1789-1848. Trad. de Maria Tereza Lopes Teixeira e Marcos Penchel. Rio de Janeiro: Paz e Terra, 1977. 
Artigo original

Hegemonia - Revista Eletrônica de Relações Internacionais do Centro Universitário Unieuro

ISSN: $1809-1261$

UNIEURO, Brasília, número 15, 2015, pp. 17-41.

KANT, Imamnuel. Fundamentação da Metafísica dos Costumes. Edições 70: Lisboa, 2007. - Resposta a pergunta: Que é esclarecimento? Textos Seletos. Tradução Floriano de Sousa Fernandes. 3 ed. Editora Vozes: Petrópolis, RJ. 2005. Pg. 63-71.

LOCKE, John. Segundo tratado sobre o governo. 3. ed. São Paulo: Abril Cultural, 1983.

PATEMAN, Carole. O contrato sexual. Rio de Janeiro: Paz e Terra, 1993.

QUIJANO, Aníbal. Colonialidade do poder, eurocentrismo e América Latina. In: A colonialidade do saber: eucorentrismo e ciências sociais. In: Perspectivas latino-americanas. Edgar Lander (organizador). 7. ed. Argentina: Clacso, 2005. p. 227-278.

RUSSEL, Bertrand. História do pensamento ocidental. Tradução: Laura Alves e Aurélio Rebello. Rio de Janeiro: Ediouro, 2004 (Clássicos de ouro ilustrados).

SANTANDER, Carlos Ugo Joo; RIBEIRO, Andrey Borges Pimentel. Direitos Humanos: uma leitura a partir de América Latina. In: Lídia de Oliveira Xavier; Carlos F. Domínguez Avila; Vicente Fonseca. (Org.). Direitos Humanos, Cidadania e Violência no Brasil: estudos disciplinares. 1ed. Curitiba: CRV, 2014, v. 2, p. 271-286.

SANTANDER, Carlos Ugo Joo. Direitos e igualdades em tempos de globalização: desafios contemporâneos. Em Debate (Belo Horizonte), v. 3, p. 6-12, 2011.

VILLEY, Michel. O direito e os direitos humanos. São Paulo: Martins Fontes, 2007. 